\title{
An Optimal Investment Model for Single Supplier-Single Customer Partnership Performance Improvement in Shipbuilding Supply Chains
}

\author{
K. S. C. Raju ${ }^{1}$, L. G. Marujo ${ }^{2} \&$ R. Y. Qassim ${ }^{3}$ \\ ${ }^{1}$ Department of Ocean Engineering and Naval Architecture, Indian Institute of Technology Kharagpur, \\ Kharagpur, India \\ ${ }^{2}$ Department of Production Engineering, POLI, Federal University Rio de Janeiro, Rio de Janeiro, Brazil \\ ${ }^{3}$ Department of Ocean Engineering, COPPE, Federal University of Rio de Janeiro, Rio de Janeiro, Brazil \\ Correspondence: Qassim, R. Y., Department of Ocean Engineering, COPPE, Federal University of Rio de \\ Janeiro, Rio de Janeiro, Brazil. E-mail: raadqassim@hotmail.com
}

Received: February 18, 2013

Accepted: March 5, 2013

Online Published: May 16, 2013

doi:10.5539/ijbm.v8n11p85

URL: http://dx.doi.org/10.5539/ijbm.v8n11p85

\begin{abstract}
A mathematical programming model employing activity-based costing is developed for material procurement performance improvement in a single supplier-single customer environment in shipbuilding. Four types of activities are identified as targets of cost reduction: supplier caused (reflected) and customer caused (reflected) activities. Complete information exchange is assumed between supplier and customer, with a view to obtaining maximum cost reduction through joint investments by the supplier and the customer, subject to their budgetary constraints. A real case of shipbuilding of boats and barges for inland waterways in the Amazon region in Brazil is used to test the applicability and utility of the mixed integer programming model.
\end{abstract}

Keywords: supply chain, supplier customer, partnership

\section{Introduction}

In shipbuilding and offshore plant construction, project production is considered to be the most adequate approach, whereby the final product is a ship or an offshore petroleum exploration and production platform. Within project production systems, shipbuilding is one of the most challenging from the point of view of production planning and control, in view of the long lead time involved, as the construction of a ship typically takes 1-2 years. As a consequence, shipbuilding entails significant risks of time and cost overruns. In addition to project planning itself, shipbuilding planning and control encompasses shopfloor scheduling, dynamic layout determination, spatial allocation, outfitting planning, and component and raw material procurement. All of these aspects need to be integrated in overlapping short-term, medium-term, and long-term planning horizons. An overview of shipbuilding may be found in Bruce and Garrard (1999).

In view of the above, the selection of a supply chain strategy in shipbuilding is far from straightforward, as shown by Sanderson and Cox (2008) employing a case study of a naval shipyard in the UK. The major reason for this is the large number of purchased components and the production of subassemblies and blocks that are inherent in the building of a naval vessel, which possesses features of recurrent construction systems (Schmitt and Faaland, 2004) and construction projects (Bankvall et al., 2010; Qassim, 2012).

The construction of a ship consists of two major tasks:

(1) Ship structure, which comprises the fabrication of parts and the production of subassemblies and blocks.

(2) Outfitting of piping, pumps, motors, and other machinery.

In view of the different characteristics of each of these tasks, the corresponding material procurement problems that are encountered are distinct. The principal raw material for ship structure construction is steel, as opposed to outfitting where a wide spectrum of components is acquired for embedding into the ship structure.

With a view to enhancing competitiveness in shipbuilding, there has been in the last two decades a strategic reduction of the steel supplier base. In fact, the clear tendency is towards a single supplier. In this context, Kim et al. (2007) report on the use of extended enterprise resource planning in the procurement of steel plates in a single supplier-single customer partnership between Pohang Steel Company and Daewoo Shipbuilding and 
Marine Engineering Company. The emergence of extended enterprise resource planning systems has enabled this type of partnership, not only in shipbuilding but also in other areas; see, for example, Mǿller (2005). Single supplier-single customer partnerships have been shown to possess numerous advantages, the principal of which is the feasibility of the implementation of continuous procurement performance improvement programme.

Needles to say, as in all supply chain partnership types, risks are present and need to be carefully assessed; see, for example, Manuj and Mentzer (2008).

An extensive literature exists on various aspects of single supplier-single customer partnerships. Costantino and Pellegrino (2010) present a real options model which may be employed as a decision support tool in single versus multiple sourcing. Laeequddin and Sardana (2010) employ a case study approach to assessing the question of trust building in single supplier-single customer partnerships. Jha and Shanker (2009) present a production-inventory model for single supplier-single customer partnerships, where materials deplete with constant decay rates. Ho et al. (2010) provide a review of multicriteria approaches to the problem of supplier evaluation and selection. In the particular case of shipbuilding, Ruuska et al. (2012) have shown that customers and suppliers diverge in theie respective evaluation of supplier delivery performance. As a result, it is of crucial importance to develop a reliable framework for the appropriate assessment of supply chain performance upon which there is reasonable agreement of both supplier and customer.

The subject of interest in this paper lies within the domain of procurement performance improvement through investment in the single supplier-single customer environment. This problem is part of a larger problem which is that of supplier-customer contract optimisation, on which a rather extensive literature exists. Of particular relevance is the work of Noonan and Wallace (2006) who emply surveys to present a framework for the optimisation of supplier-customer contracts. Concentrating on the single customer-single supplier variant of this problem, two recent contributions are provided by Roels et al. (2010) and Wang (2010). In the former, a number of contract types are analised with a view to procurement efficiency maximisation. In the latter, the maintenance contract optimisation problem is modelled on the premise that there exists one sole service provider.

One of the central facets of procurement performance improvement in single supplier-single customer partnerships is the question of investment by the partner pair in the aforementioned performance improvement effort, particularly in long-term supplier-customer partnerships as is the case in the procurement of steel in shipbuilding. A recent contribution in this direction is provided by Talluri et al. (2010), who develop a set of optimisation models for the multiple supplier-single customer and the multiple supplier-dual customer cases, where the focus is on supply risk minimisation whilst at the same time allowing for an acceptable rate of return from supplier development investments. To the authors'knowledge, there does not exists reported work on material procurement performance improvement for the single supplier-single customer case, except for that of Hsieh and Liu (2010) in which the focus is on the single supplier-single customer case, each of whom possesses imperfect production and inspection processes. In view of this fact, both supplier and customer invest so as to reduce defective items being produced. Towards this end, they employ noncooperative game theory models. It is precisely this gap in single supplier-single customer case that the present work is inserted.

In this work, the focus is on cost reduction in steel material procurement in shipbuilding, noting that the approach presented in this paper is also applicable to other manufacturing environments. The framework that is employed is that of mathematical programming, along with activity based costing, these being two pillars in the strategic analysis of firm performance (Shapiro 1999), noting that procurement performance has become a critical part of the overall performance of a firm (Eom et al. 2008). Frameworks for the application of activity-based costing in supply chains has been reported recently by Schulz et al. (2010) and Ayvaz and Pehlivanh, D. (2011).

The paper is organised as follows. In Section 2, the problem under consideration is described. The mathematical model of the problem is formulated in Section 3. This is followed, in Section 4, by the aplication of the model to a real case which is drawn from a shipyard in the Amazon Region in Brazil. The paper is concluded in Section 5 with an evaluation of the model and possible extensions as suggestions for future research work.

\section{Problem Description}

A single supplier-single customer partnership is under consideration. In this Section, a description is presented of the essential features of the problem. Upon receipt of goods from the supplier, the customer executes a number of additional activities to those agreed to in the delivery contract. An example is that of a split delivery of goods by the supplier which needs additional inspection and setup activities to be carried out by the customer. Another example is that of low quality goods furnished by the supplier, these needing additional inspection time and production stops on the part of the customer. 
These additional activities caused by the activities of the supplier in the environment of the customer normally may be reflected to cause additional activities in the environment of the supplier. For example, the delivery of a lot with an unacceptable defect level, and therefore returned by the customer to the supplier, causes additional activities in the environment of the supplier in the way of quality inspection planning and production setup.

A mirror image occur vis-à-vis the customer. Thus, the customer may cause additional activities in the environment of the supplier. For example, if the customer decides to reduce lot size, then the supplier is obliged to increase delivery frequency, which by reflection, causes an increase in the number of inspections carried out by the customer.

Summing up, there are four types of activities that are additional to those defined in the single supplier-single customer contract: additional (reflected) activities by the supplier (customer). Each type of this activity quartet incurs costs, which affect the performance of the single supplier-single customer partnership. In order to take into account the occurrence of this type of activity, it is necessary to make investments for cost reduction, so as to improve the performance of the partnership.

A precise problem statement is now provided. The following are given:

(1) A set of activities which consists of four subsets of activities: those caused by the supplier, those reflected by the customer, those caused by the customer, and those reflected by the supplier.

(2) With each activity member of the supplier and the customer causal activity subsets, the following attributes are associated: present cost value, target cost value, post-investment achieved cost value, present value of cost driver level, target value of cost driver level, target value of cost driver level, unit investment cost reduction value of activity cost, and unit investment cost reduction value of activity cost driver level.

(3) With each activity member of the supplier and the customer reflection activity costs, the following attributes are associated: present cost value, target cost value, post-investment achieved cost value, and unit investment cost reduction value of activity cost.

(4) With each of the supplier and the customer, an available budget value is allocated for procurement performance improvement.

It is required to determine the set of post-investment achieved values and levels of activity costs and activity cost drivers, respectively, so as to maximise the total cost reduction subject to budgetary limitation.

\section{Model Formulation}

Prior to the statement of the mathematical model, necessary notation is introduced.

\subsection{Notation}

a-superscript denoting achieved level.

c-subscript denoting customer.

i-subscript for activity caused by supplier.

j-subscript for activity reflected by customer.

k-subscript for activity caused by customer.

l-subscript for activity reflected by supplier.

p-superscript denoting present level.

r-subscript for activity reflection.

s-superscript denoting supplier.

t-superscript denoting target level.

$\mathrm{C}^{\mathrm{scp}}{ }_{\mathrm{i}}$-present value of cost of activity i caused by supplier.

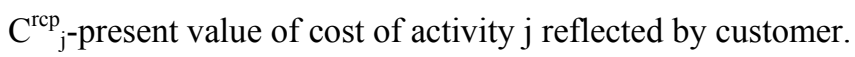

$\mathrm{C}^{\mathrm{csp}} \mathrm{k}_{\mathrm{k}}$-present value of cost of activity $\mathrm{k}$ caused by customer.

$\mathrm{C}^{\text {rsp }}{ }_{1}$-present value of cost of activity 1 reflected by supplier.

$\mathrm{C}^{\text {sct }}{ }_{\mathrm{i}}$-target value of cost of activity i caused by supplier.

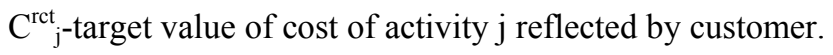

$\mathrm{C}^{\text {cst }}$-target value of cost activity $\mathrm{k}$ caused by customer. 
$\mathrm{C}^{\text {rst }}$-target value of cost activity 1 reflected by supplier.

$\mathrm{C}^{\text {sca }}{ }_{\mathrm{i}}$-achieved value of cost of activity $\mathrm{i}$ caused by supplier.

$\mathrm{C}^{\text {rca }}{ }_{\mathrm{j}}$-achieved value of cost of activity $\mathrm{j}$ reflected by customer.

$\mathrm{C}^{\mathrm{csa}} \mathrm{k}^{\mathrm{k}}$-achieved value of activity $\mathrm{k}$ caused by customer.

$\mathrm{C}^{\text {rsa }}{ }_{1}$-achieved value of cost of activity 1 reflected by supplier.

$\mathrm{D}^{\mathrm{scp}}{ }_{\mathrm{i}}$-present level of cost driver of activity $\mathrm{i}$ caused by supplier.

$\mathrm{D}^{\mathrm{rcp}}{ }_{\mathrm{j}}$-present level of cost driver of activity $\mathrm{j}$ reflected by customer.

$\mathrm{D}^{\mathrm{csp}} \mathrm{k}$-present level of cost driver of activity $\mathrm{k}$ caused by customer.

$\mathrm{D}^{\mathrm{rsp}}{ }_{1}$-present level of cost driver of activity 1 reflected by supplier.

$\mathrm{D}^{\text {sct }}{ }$-target level of cost driver of cativity i caused by supplier.

$\mathrm{D}^{\text {rct }}{ }_{\mathrm{j}}$-target level of cost driver of activity $\mathrm{j}$ reflected by customer.

$\mathrm{D}^{\text {cst }}{ }_{\mathrm{k}}$-target level of cost driver of activity $\mathrm{k}$ caused by customer.

$\mathrm{D}^{\text {rst }}{ }_{1}$-target level of cost driver of activity 1 reflected by supplier.

$\mathrm{D}^{\mathrm{sca}} \mathrm{i}_{\mathrm{i}}$-achieved level of cost driver of activity i caused by supplier.

$D^{\text {rca }}{ }_{j}$-achieved level of cost driver of activity $j$ reflected by customer.

$\mathrm{D}_{\mathrm{k}}^{\mathrm{csa}}$-achieved level of cost driver of activity $\mathrm{k}$ caused by customer.

$\mathrm{D}^{\text {rsa }}{ }_{1}$-achieved level of cost driver of activity 1 reflected by supplier.

$\mathrm{E}^{\mathrm{csc}} \mathrm{i}$-unit investment cost of cost reduction of activity $i$ caused by supplier.

$\mathrm{E}^{\mathrm{dsc}}{ }_{\mathrm{i}}$ - unit investment cost of cost driver level reduction of activity i caused by supplier.

$\mathrm{E}^{\mathrm{crc}}{ }_{\mathrm{j}}$-unit investment cost of cost reduction of activity $\mathrm{j}$ reflected by customer.

$\mathrm{E}^{\mathrm{ccs}}{ }_{\mathrm{k}}$-unit investment cost of cost reduction of activity of $\mathrm{k}$ caused by customer.

$\mathrm{E}_{\mathrm{k}}^{\mathrm{dcs}}$-unit investment cost of cost driver level reduction of activity $\mathrm{k}$ caused by customer.

$\mathrm{E}^{\mathrm{crs}}{ }_{1}$-unit investment cost of cost reduction of activity 1 reflected by supplier.

$\mathrm{F}^{\mathrm{c}}$-total available budget of customer.

$\mathrm{F}^{\mathrm{s}}$-total available budget of supplier.

$\mathrm{I}^{\mathrm{csc}}$-total investment cost of cost reduction of activities caused by supplier.

$\mathrm{I}^{\mathrm{dsc}}$-total investment cost of cost driver level reduction of activities caused by supplier.

$\mathrm{I}^{\mathrm{crc}}$-total investment cost of cost reduction of activities reflected by customer.

$\mathrm{I}^{\mathrm{ccs}}$-total investment cost of cost reduction of activities caused by customer.

$\mathrm{I}^{\mathrm{dcs}}$-total investment cost of cost driver level reduction of activities caused by supplier.

$\mathrm{I}^{\mathrm{crs}}$-total investment cost of cost reduction of activities reflected by supplier.

$\mathrm{S}^{\text {sc }}$-cost reduction of activities caused by supplier.

$\mathrm{S}^{\mathrm{rc}}$-cost reduction of activities reflected by customer .

$\mathrm{S}^{\mathrm{cs}}$-cost reduction of activities caused by customer.

$\mathrm{S}^{\mathrm{rs}}$-cost reduction of activities reflected by supplier.

\subsection{Model Statement}

The mathematical model may be stated as follows.

Maximise

$$
S^{s c}+S^{r c}+S^{c s}+S^{r s}
$$

subject to

$$
\begin{aligned}
& S^{s c}=\sum_{i}\left(C^{s c p}{ }_{i} \times D^{s c p}{ }_{i}-C^{s c a}{ }_{i} \times D_{i}^{s c a}{ }_{i}\right) \\
& S^{r c}=\sum_{j}\left(C^{r c p}{ }_{j} \times D^{r c p}{ }_{j} C^{r c a}{ }_{j} \times D^{r c a}{ }_{j}\right)
\end{aligned}
$$




$$
\begin{aligned}
& S^{c s}=\Sigma_{k}\left(C^{c s p}{ }_{k} \times D^{c s p}{ }_{k}-C^{c s a}{ }_{k} \times D^{c s a}{ }_{k}\right) \\
& S^{r s}=\Sigma_{l}\left(C^{r s p}{ }_{l} \times D^{r s p}{ }_{l}-C^{r s a}{ }_{l} \times D^{r s a}{ }_{l}\right) \\
& I^{c s c}=\Sigma_{i} E^{c s c}\left(C^{c c p}{ }_{i}-C^{s c a}{ }_{i}\right) \\
& I^{d s c}=\sum_{i} E^{d s c}{ }_{i} \times\left(D^{s c p}{ }_{i}-D^{s c a}{ }_{i}\right) \\
& I^{c r c}=\sum_{j} E_{j}^{c r c} \times\left(C^{r c p}{ }_{j}-C^{r c a}{ }_{j}\right) \\
& I^{c c s}=\sum_{k} E^{c c s}{ }_{k} \times\left(C^{c s p}{ }_{k}-C^{c s a}{ }_{k}\right) \\
& I^{d c s}=\sum_{k} E_{k}^{d c s} \times\left(D_{k}^{c s p}-D_{k}^{c s a}\right) \\
& I^{\text {crs }}=\sum_{l} E^{\text {crs }}{ }_{l} \times\left(C^{r s p}{ }_{l}-C^{r s a}{ }_{l}\right) \\
& I^{c s c}+I^{d s c}+I^{c r c}+I^{c c s}+I^{d c s}+I^{c r s} \leq F^{s}+F^{c} \\
& C^{\mathrm{sca}}{ }_{i} \leq C^{\mathrm{scp}}{ }_{i}, \forall i \\
& C^{s c a}{ }_{i} \geq C^{s c t}{ }_{i}, \quad \forall i \\
& D^{s c a}{ }_{i} \leq D^{s c p}{ }_{i} \quad \forall i \\
& D^{s c a}{ }_{i} \geq D^{s c t}{ }_{i}, \quad \forall i \\
& C^{r c a}{ }_{j} \leq C^{r c p}, \forall j \\
& C^{r c a}{ }_{j} \geq C^{r c t}, \forall j \\
& C^{c s a}{ }_{k} \leq C^{c s p}{ }_{k}, \quad \forall k \\
& C^{c s a}{ }_{k} \geq C^{c s t}{ }_{k}, \quad \forall k \\
& D^{c s a}{ }_{k} \leq D^{c s p}{ }_{k}, \quad \forall k \\
& D^{c s a}{ }_{k} \geq D^{c s t}{ }_{k}, \forall k \\
& C^{r s a}{ }_{l} \leq C^{r s p}{ }_{l} \quad \forall l \\
& C^{r s a}{ }_{l} \geq C^{r s t}{ }_{b}, \quad \forall l
\end{aligned}
$$

Objective function (1) depicts the total cost reduction obtained as a consequence of the procurement performance improvement investments jointly made by the supplier and customer. Constraints (2)-(5) express the four types of cost reduction which may be obtained, as described in Section 2. Constraints (6)-(11) define the types of investment that are made by the supplier and the customer. Constraint (12) ensures that the total investment in procurement performance improvement which is made by the supplier and the customer does not exceed the total budget available. Constraints (13)-(26) define the domain of the decision variables.

The model given by (1)-(26) constitutes a nonlinear mixed integer programming model. In the following Subsections, we discuss in turn its input parameters and output variables.

\subsection{Input Parametersu}

The model possesses three sets of input parameters as follows.

(1) Present levels of activity costs and activity cost drivers.

(2) Target levels of activity costs and activity cost drivers.

(3) Unit investment costs of reduction of levels of activity costs and activity cost drivers.

(4) Supplier and customer budgetary levels.

Assuming that both supplier and customer employ activity based costing in their respective costing systems, which are nowadays widespread data for the first two sets of input parameters, should be readily available. On the other hand, data for the third set of input parameters are not easy to find and their estimation should be part of the procurement performance improvement effort. It is worth noting that though a linear relationship is assumed in constraints (7)-(12), this can be substituted by a nonlinear linearship if appropriate, depending on the estimation model for this input data set; however, at the present time, it appears more reasonable to assume a linear relationship in view of data scarcity. Values of the fourth set of input data would in practice be the result of supplier-customer negotiation, and may well be determined as part of the optimisation of the procurement contract. 


\subsection{Output Variables}

There are two sets of output variables in the model as follows.

(1) Continuous activity achieved cost values.

(2) Binary activity achieved cost driver levels.

The values of the output variables, which are obtained from the solution of the model, serve as a measure of the optimal procurement performance improvement effort.

\section{Application}

In order to illustrate the use of the model, an example is drawn from shipbuilding practice in a large shipyard in the Amazon region in Brazil, where tow boats and barges are constructed for inland waterways transportation, which constitutes the major transportation mode in this region. The numerical data that are employed are essentially typical of those encountered in practice. Input data are grouped into four subsets; i.e., activities caused by the supplier for the customer, activities reflected by the customer to the supplier, activities caused by the customer for the supplier, and activities reflected by the supplier to the customer. The models for each example are computationally implemented employing the commercial optimisation software LINGO (2008).

\subsection{Example Description}

There are five activities which are caused by the supplier for the customer, these being planning, reception, production stop, adjustment, and administration. Input data corresponding to this activity subset are summarised in (Table 1). These activities result in a subset of activities reflected by the customer to the supplier, these being support, production stop, adjustment, and delivery. (Table 2) shows input data related to the aforementioned subset of activities. In a similar fashion, the customer causes five activities for the supplier; i.e., planning, support, production stop, delivery, and adjustment. Their corresponding input data are summarised in (Table 3). In turn, the latter subset of activities leads to reflected activities by the supplier to the customer. Input data related to this activity subset are shown in (Table 4). Supplier and customer budgetary data are given in (Table $5)$.

Table 1. Activities provoked by the supplier for the customer

\begin{tabular}{cccccccc}
\hline $\mathbf{i}$ & Activity & Cscp & Csct & Dscp & Dsct & Ecsc & Edsc \\
\hline 1 & Planning & 600 & 480 & 8 & 6 & 10 & 100 \\
2 & Reception & 500 & 450 & 3 & 2 & 10 & 100 \\
3 & Production stop & 250 & 225 & 100 & 90 & 10 & 10 \\
4 & Ajustment & 1250 & 1135 & 16 & 12 & 10 & 100 \\
5 & Administration & 300 & 270 & 3 & 2 & 10 & 100 \\
\hline
\end{tabular}

Table 2. Activities reflected by the customer to the supplier

\begin{tabular}{ccccc}
\hline J & 1 & 2 & 3 & 4 \\
\hline Activity & Support & Adjustment & Production stop & Delivery \\
\hline D1rc & 0 & 0 & 0 & 0 \\
D2rc & 3 & 0 & 0 & 0 \\
D3rc & 3 & 1 & 1 & 1 \\
D4rc & 3 & 0 & 0 & 0 \\
D5rc & 0 & 0 & 0 & 0 \\
Crcp & 300 & 250 & 1000 & 1800 \\
Crct & 250 & 230 & 895 & 1550 \\
Ecrc & 8 & 9 & 10 & 12 \\
\hline
\end{tabular}


Table 3. Activities provoked by the customer for the supplier

\begin{tabular}{cccccccc}
\hline $\mathbf{k}$ & Activity & Cesp & Ccst & Desp & Dest & Eccs & Edcs \\
\hline 1 & Planning & 300 & 250 & 4 & 2 & 11 & 90 \\
2 & Suport & 400 & 300 & 2 & 1 & 9 & 100 \\
3 & Production stop & 400 & 350 & 50 & 40 & 11 & 10 \\
4 & Delivery & 950 & 900 & 12 & 8 & 10 & 110 \\
5 & Ajustment & 250 & 200 & 3 & 2 & 10 & 100 \\
\hline
\end{tabular}

Table 4. Activities reflected by the supplier to the customer

\begin{tabular}{ccccc}
\hline L & $\mathbf{1}$ & $\mathbf{2}$ & $\mathbf{3}$ & $\mathbf{4}$ \\
\hline Activity & Reception & Production stop & Adjustment & Administration \\
\hline D1rs & 0 & 0 & 0 & 0 \\
D2rs & 0 & 0 & 0 & 1 \\
D3rs & 0 & 1 & 1 & 1 \\
D4rs & 1 & 0 & 0 & 0 \\
D5rs & 0 & 0 & 0 & 0 \\
Crsp & 300 & 260 & 900 & 280 \\
Crst & 250 & 230 & 825 & 250 \\
Ecrs & 9 & 11 & 8 & 12 \\
\hline
\end{tabular}

Table 5. Supplier and customer budgetary data

\begin{tabular}{cc}
\hline Supplier budget (Fs) & Customer budget (Fc) \\
\hline 500 & 750 \\
\hline
\end{tabular}

\subsection{Example Results}

In Tables 6-9, the results obtained by the application of the optimisation model to this example are displayed. These results have been employed in the shipyard under study to guide the investment effort by both steel material supplier and shipbuilder. As can be observed, the numerical results provide details on all procurement activities, as described in Section 2.

Table 6. Investment results

\begin{tabular}{ccccc}
\hline Ssc & Src & Scs & Srs & Total \\
\hline$\$ 9.390,00$ & $\$ 5.750,00$ & $\$ 7.800,00$ & $\$ 2.020,00$ & $\$ \mathbf{2 4 . 9 6 0 , 0 0}$ \\
\hline
\end{tabular}

Table 7. Achieved level of cost drivers

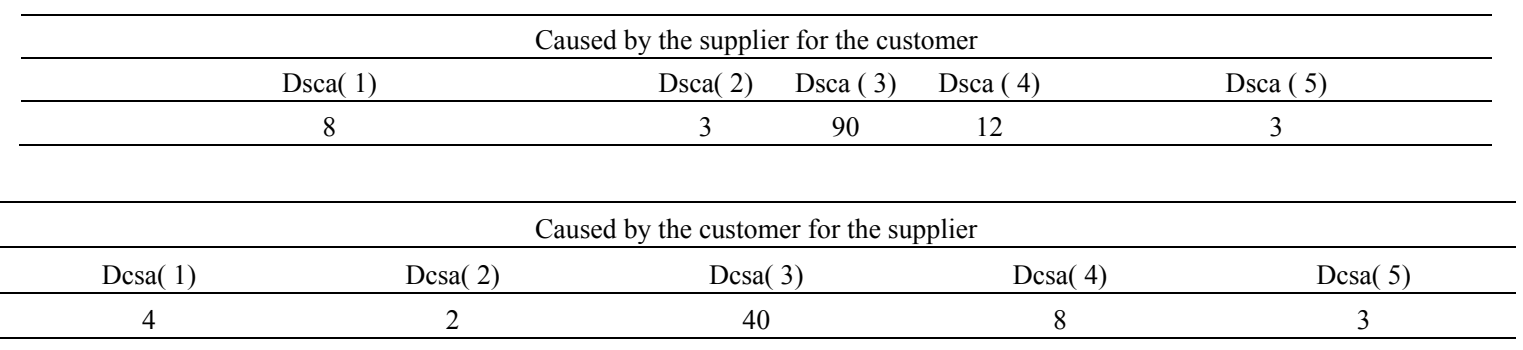

Table 8. Cscai-achieved value of cost of activity i caused by supplier

\begin{tabular}{cc}
\hline Planning & 600 \\
\hline Suport & 500 \\
Production_Stop & 229 \\
Delivery & 1250 \\
Adjustment & 300 \\
\hline
\end{tabular}


Table 9. Crcaj-achieved value of cost of activity j reflected by customer

\begin{tabular}{cl}
\hline Support & 300 \\
\hline Adjustment & 260 \\
Production_Stop & 900 \\
Delievery & 280 \\
\hline
\end{tabular}

Table 10. Ccsak-achieved value of activity $\mathrm{k}$ caused by customer

\begin{tabular}{cl}
\hline Planning & 300 \\
\hline Suport & 400 \\
Production_Stop & 400 \\
Delivery & 950 \\
Adjustment & 250 \\
\hline
\end{tabular}

Table 11. Crsal-achieved value of cost of activity 1 reflected by supplier

\begin{tabular}{cc}
\hline Reception & 300 \\
\hline Production_Stop & 250 \\
Adjustment & 1000 \\
Administration & 1800 \\
\hline
\end{tabular}

\section{Conclusions}

The mathematical programming model employing an activity - based costing framework that is developed in this paper has been shown to be useful in the determination of optimal investments in the performance improvement of single supplier-single customer partnerships. It has been employed successfully in steel procurement in shipbuilding of boats and barges for inland waterways transportation in the Amazon region in Brazil. Possible extensions of the model include multiple supplier-single customer partnerships, multiple level supply chains, as in Jolayemi (2010) and the introduction of multiple periods for employment in longer time horizons, as in Khataie et al (2011).

\section{Acknowledgements}

This work would not have been possible without the support of Rebelo Ind. Com. E Nav. Ltda., in the Amazon region in Brazil, for which the authors take this opportunity to express their thanks. One of the authors (RYQ) wishes to thank the Brazilian National Research Council (CNPq) for a scholarship during the research work reported this paper.

\section{References}

Ayvaz, A., \& Pehlivanh, D. (2011). The use of time driven activity based costing and analytic hierarchy process metghod in balanced scorecard implementation. International Journal of Business and Management, 6(3), 146-158.

Bankvall, L., Bygballe, L. E., Dubois, A., \& Jahre, M. (2010). Interdependence in supply chains and projects in construction. Supply Chain Mangement: An International Journal, 15(5), 385-393. http://dx.doi.org/10.1108/13598541011068314

Bruce, G. J., \& Garrard, I. (1999). The Business of Shipbuilding (1st ed.). LLP, London and Hong Kong.

Costantino, N., \& Pellegrino, R. (2010). Choosing between single and multiple sourcing based on supplier default risk: A real options approach. Journal of Purchasing and Supply Management, 16(1), 27-40. http://dx.doi.org/10.1016/j.pursup.2009.08.001

Ho, W., Xu, X., \& Dey, P. K. (2010). Multi-criteria decision making approaches for supplier evaluation and selection: A literature review. European Journal of operational Research, 202(1), 16-24. http://dx.doi.org/10.1016/j.ejor.2009.05.009

Hsieh, C. C., \& Liu, Y. T., (2010). Quality improvement and inspection policy in a supplier-manufacturer supply chain. European Journal of Operational Research, 202(3), 717-729. http://dx.doi.org/10.1016/j.ejor.2009.06.013 
Eom, C. S. J., Yun, S. H. Y., \& Paek, J. H. (2008). Subcontractor evaluation and management framework for strategic planning. ASCE Journal of Construction Engineering and Management, 134(11), 842-851. http://dx.doi.org/10.1061/(ASCE)0733-9364(2008)134:11(842)

Jha, J. K., \& Shanker, K. (2009). A single-vendor single-buyer production-inventory model with controllable lead time and service level constraint for decaying items. International Journal of Production Research, 47(24), 6875-6898. http://dx.doi.org/10.1080/00207540802398053

Jolayemi, J. K. (2010). Optimum production-distribution and transportation planning in three-stage supply chains. International Journal of Business and Management, 5(12), 29-40.

Khartaie, A. H., Bulgak, A. A., \& Segovia, J. J. (2011). Activity-based costing and management applied in a hybride Decisio support System for order management. Decision Support Systems, 142-156. http://dx.doi.org/10.1016/j.dss.2011.06.003

Kim, I., Park, H. C., Han, S., Han, T., Kim, T., \& Lee, H. (2007). Process innovation along the steel supply chain between global shipbuilder and steel company with the extended ERP system. International Conference on Computer Applications in Shipbuilding, 18-20.

Laeequddin, M., \& Sardana, G. D. (2010). What breaks trust in customer supplier relationship? Management Decision, 48(3), 53-365. http://dx.doi.org/10.1108/00251741011037738

LINDO Systems Inc. (2008). LINGO User's Manual. Chicago, Illinois.

Manuj, I., \& Mntzer, J. T. (2008). Global supply risk management. Journal of Business Logistics, 29(1), 133-155. http://dx.doi.org/10.1002/j.2158-1592.2008.tb00072.x

Mǿller, C. (2005). ERPII: a conceptual framework for next-generation enterprise systems. Journal of Enterprise Information Management, 18(4), 483-497. http://dx.doi.org/10.1108/17410390510609626

Noonan, J., \& Wallace, M. (2006). Improved optimisation through advanced relationship planning. Supply Chain Management: an International Journal, 11(6), 483-490. http://dx.doi.org/10.1108/13598540610703873

Qassim, R. Y. (2012). Integrated process planning and production scheduling and multimode resource constrained project scheduling: ship block assembly application. In F. Abdul Aziz (Ed.), Manufacturing System (pp. 307-314).

Roels, G., Karmarkar, U. S., \& Carr, S. (2010). Contracting for collaborative services. Management Science, 56(5), 849-863. http://dx.doi.org/10.1287/mnsc.1100.1146

Ruuska, I., Ahola, T., Martinsuo, M., \& Westerholm, T. (2012). Supplier capabilities in large shipbuilding projects. International Journal of Project Management. http://dx.doi.org/10.1016/j.ijproman.2012.09.017

Sanderson, J., \& Cox, A. (2008). The challenge of supply strategy selection in a project environment: evidence from UK naval shipyard. Supply Chain Management: an International Journal, 13(1), 16-25. http://dx.doi.org/10.1108/13598540810850283

Schmitt, T., \& Faaland, B. (2004). Scheduling recurrent construction. Naval Research Logistics, 51(8), 1102-1128. http://dx.doi.org/10.1002/nav.20043

Schulz, M., Seuring, S., \& Ewering, C. (2010). Applying activity-based costing in a supply chain environment. $\begin{array}{lllll}\text { International Journal of Production } & \text { Economics, } & \text { 135(2), }\end{array}$ http://dx.doi.org/10.1016/j.ijpe.2011.10.005

Shapiro, J. F. (1999). On the connections among activity-based costing, mathematical programming models for analyzing decisions, and the resource-based view of the firm. European Journal of Operational Research, 118, 295-314. http://dx.doi.org/10.1016/S0377-2217(99)00027-2

Spicknall, M. H. (1997). Scheduling methods for ship build strategy development: Literature search and research report for the midterm sealift generic build strategy task. University of Michigan Transportation Institute, Marine Systems Division, UMTRI-97-29.

Talluri, S., Narasmihan, R., \& Chung, W. (2010). Manufacturer cooperation in supplier development under risk. European Journal of Operational Research, 207, 165-173. http://dx.doi.org/10.1016/j.ejor.2010.03.041

Wang, W. (2010). A model for maintenance service contract design, negotiation and optimization. European Journal of Operational Research, 201, 239-246. http://dx.doi.org/10.1016/j.ejor.2009.02.018 